\title{
Facile Preparation of Hierarchical Porous Carbon from Orange Peels for High-Performance Supercapacitor
}

\author{
Chun Xu, Zhiyong Hu, Xing Wang, Chunyan Wang, Dejuan Huang ${ }^{*}$ Yong Qian
}

School of Chemistry, Biology and Material Science, East China University of Technology, Nanchang 330013, P.R. China

*E-mail: $419713241 @$ qq.com

doi: $10.20964 / 2021.03 .07$

Received: 13 October 2020 / Accepted: 23 December 2020 / Published: 31 January 2021

In this study, resource-rich, renewable, and low cost orange peel was used as the precursor for the synthesis of hierarchical porous carbon (HPC). HPC was prepared by activation through etching with potassium hydroxide solution and one-step pyrolysis. Employing SEM, TEM, and other characterization methods, the micro-morphology and structure of HPC were analyzed, and its electrochemical performance was evaluated. Results show that the HPC material had a high specific surface area of $864.78 \mathrm{~m}^{2} / \mathrm{g}$, excellent capacitance performance $\left(264 \mathrm{Fg}^{-1}\right.$ at $\left.1 \mathrm{~A} / \mathrm{g}\right)$ and long-term cyclic stability (specific capacitance retention reached $95.36 \%$ after 2000 charge-discharge cycles). Even when the current density was increased 10 times, the capacitance was $242 \mathrm{Fg}^{-1}(10 \mathrm{~A} / \mathrm{g})$. Its performance was much better than typical carbon materials. This study provides a way to effectively use biomass resources to prepare cost-effective activated carbon materials for supercapacitors in energy storage.

Keywords: Hierarchical porous carbon; Orange peels; Supercapacitors; Electrochemical performance

\section{$\underline{\text { FULL TEXT }}$}

(C) 2021 The Authors. Published by ESG (www.electrochemsci.org). This article is an open access article distributed under the terms and conditions of the Creative Commons Attribution license (http://creativecommons.org/licenses/by/4.0/). 